\title{
What is chiropractic?
}

\author{
Jan Hartvigsen ${ }^{1,2^{*}}$ (D) and Simon French ${ }^{3,4}$
}

\begin{abstract}
While in some jurisdictions chiropractic is fully integrated in public and insurance funded health care systems, in others it is outside and considered as complementary or alternative health care. There is a paucity of data and rigorous scientific studies regarding most aspects of chiropractic practice although research activity has been increasing in recent years. We call for papers for a thematic series in Chiropractic and Manual Therapies that can help define chiropractic better to stakeholders inside and outside the profession under the theme What is Chiropractic?
\end{abstract}

Keywords: Chiropractic, Editorial, Health policy

\section{Background}

In 2002, Meeker and Haldeman wrote that "In today's dynamic health care milieu, chiropractic stands at the crossroads of mainstream and alternative medicine" [1]. Fifteen years later the global identity and place for chiropractic in healthcare is still unresolved. From within chiropractic, one end of the spectrum subscribes to " $a$ philosophy of neo-vitalism" and "a neurologicallycentered model of subluxation" [2], while the other end promotes that "chiropractic education should be ......... founded on the principles of evidence-based care" and "the teaching of vertebral subluxation complex as a vitalistic construct that claims that it is the cause of disease is unsupported by evidence" [3]. In some parts of the world chiropractors are highly integrated in insurance or government funded healthcare programs and educated in government funded universities, whereas in other parts chiropractors are educated in private schools and practice as complementary and alternative practitioners completely outside of mainstream healthcare. Further, some academic authorities outside of chiropractic dismiss chiropractic as a legitimate health care profession [4], whereas others publically endorse the role of chiropractors in the management of specific health problems [5], adding to the confusion about the role the chiropractic profession plays.

\footnotetext{
* Correspondence: jhartvigsen@health.sdu.dk

${ }^{1}$ Department of Sports Science and Clinical Biomechanics, University of

Southern Denmark, Campusvej 55, 5230 Odense M, Denmark

${ }^{2}$ Nordic Institute of Chiropractic and Clinical Biomechanics, Campusvej 55,

5230 Odense M, Denmark

Full list of author information is available at the end of the article
}

The description and assessment of any healthcare profession should be based on rigorous data and scientific scrutiny rather than preconceived opinions. Although research dealing with the activities and effectiveness of the chiropractic profession is still relatively scarce compared to other musculoskeletal-focused professions [6], research productivity is increasing. Our informal search in Pubmed using the search terms "chiropractic OR chiropractor" reveals a $54 \%$ increase in publications between 2002 and 2016 (216 versus 401 publications). Hence, we have a better understanding than ever before of the education of chiropractors $[7,8]$, the types of therapies used by chiropractors [9-11], the conditions treated by chiropractors [10-13], the effectiveness [14-16] and cost-effectiveness of chiropractic care $[17,18]$, safety and side effects of chiropractic treatment $[19,20]$, and settings where chiropractors function alone or in collaboration with other healthcare providers [21-23]. In spite of this, there is still not a clear picture of what comprises the chiropractic profession, and how chiropractors contribute to the health of individual patients and populations.

It is therefore pertinent and timely to launch a thematic series of papers in Chiropractic \& Manual Therapies that will address the broad overarching question "What is chiropractic?". We hope these papers will provide a critical overview of the current state of the chiropractic profession from a global perspective. Individual articles will address fundamental issues about the chiropractic profession, including descriptions of: how the profession is placed in different countries and 
settings; the history of the profession in some countries; chiropractic education around the world; the profile of patients who seek chiropractic care; the types of care chiropractors provide; outcomes of chiropractic care; and other aspects of chiropractors, their practice, evidence base, and chiropractic care. We hope this thematic series will contribute to a clearer picture of chiropractic including an enlightened discussion, both within and outside of the chiropractic profession, of the role chiropractors play globally, and how they contribute to the health and well-being of the millions of people who seek their care every year.

\section{Conclusions}

There is a paucity of data and rigorous scientific studies regarding most aspects of chiropractic and chiropractic practice. We welcome all types of submissions to this thematic series from researchers of all backgrounds and locations.

\section{Acknowledgements}

No acknowledgements.

\section{Funding}

No funding received in support of this editorial.

\section{Availability of data and materials}

Not applicable

\section{Authors' contributions}

Jan Hartvigsen drafted the first version of the manuscript. Both authors subsequently revised and contributed until consensus was reached regarding the final version. Both authors read and approved the final manuscript.

\section{Ethics approval and consent to participate}

Not applicable

\section{Consent for publication}

Both authors approved the manuscript before submission.

\section{Competing interests}

Jan Hartvigsen is member of the Editorial Board of Chiropractic and Manual Therapies. Simon French is Deputy Editor-in-Chief of Chiropractic and Manual Therapies.

\section{Publisher's Note}

Springer Nature remains neutral with regard to jurisdictional claims in published maps and institutional affiliations.

\footnotetext{
Author details

'Department of Sports Science and Clinical Biomechanics, University of Southern Denmark, Campusvej 55, 5230 Odense M, Denmark. ${ }^{2}$ Nordic Institute of Chiropractic and Clinical Biomechanics, Campusvej 55, 5230 Odense M, Denmark. ${ }^{3}$ School of Rehabilitation Therapy, Faculty of Health Sciences, Queens University, 99 University Ave, Kingston, ON K7L 3N6, Canada. ${ }^{4}$ Department of Chiropractic, Macquarie University, Sydney NSW 2109, Australia.
}

Received: 6 September 2017 Accepted: 23 October 2017

Published online: 02 November 2017

\section{References}

1. Meeker WC, Haldeman S. Chiropractic: a profession at the crossroads of mainstream and alternative medicine. Ann Intern Med. 2002;136:216-27.
2. www.therubicongroup.org/\#/about-us/. Accessed 28 July 2017.

3. https://webcache.googleusercontent.com/search?q=cache:bwE8 IVp9MkJ: https://www.mq.edu.au/_data/assets/pdf_file/0003/175755/EducationalStatements-PDF_2017.pdf $\&$ cd $=2 \& h|=d a \& c t=c| n k \& g l=d k \& c l i e n t=$ firefox-b: Accessed 28 July 2017.

4. Ernst E. Chiropractic: a critical evaluation. J Pain Symptom Manag. 2008;35: 544-62.

5. Deyo RA. The role of spinal manipulation in the treatment of low back pain. JAMA. 2017;317:1418-9.

6. Walker BF. The new chiropractic. Chiropractic \& manual therapies. 2016;24:26

7. Humphreys BK, Peterson CK. The Swiss master in chiropractic medicine curriculum: preparing graduates to work together with medicine to improve patient care. J Chiropr Humanit. 2016;23:53-60.

8. Frutiger M, Tuchin PJ. Chiropractic curriculum mapping and congruence of the evidence for workplace interventions in work-related neck pain. J Chiropr Educ. 2017; Epub ahead of print

9. Rubinstein S, Pfeifle CE, van Tulder MW, Assendelft WJ: Chiropractic patients in the Netherlands: a descriptive study. J Manip Physiol Ther 2000, 23:557-563.

10. Leboeuf-Yde C, Hennius B, Rudberg E, Leufvenmark P, Thunman M. Chiropractic in Sweden: a short description of patients and treatment. J Manip Physiol Ther. 1997;20:507-10.

11. French SD, Charity MJ, Forsdike K, Gunn JM, Polus BI, Walker BF, Chondros P, Britt HC. Chiropractic observation and analysis study (COAST): providing an understanding of current chiropractic practice. Med J Aust. 2013;199:687-91.

12. Hartvigsen J, Sorensen LP, Graesborg K, Grunnet-Nilsson N. Chiropractic patients in Denmark: a short description of basic characteristics. J Manip Physiol Ther. 2002;25:162-7.

13. Coulter ID, Shekelle PG. Chiropractic in North America: a descriptive analysis. J Manip Physiol Ther. 2005;28:83-9.

14. Rubinstein SM, Leboeuf-Yde C, Knol DL, de Koekkoek TE, Pfeifle CE, van Tulder MW: The benefits outweigh the risks for patients undergoing chiropractic care for neck pain: a prospective, multicenter, cohort study. J Manip Physiol Ther 2007, 30:408-418.

15. Paige NM, Miake-Lye IM, Booth MS, Beroes JM, Mardian AS, Dougherty $P$, Branson R, Tang B, Morton SC, Shekelle PG. Association of Spinal Manipulative Therapy with Clinical Benefit and Harm for acute low back pain: systematic review and meta-analysis. JAMA. 2017;317:1451-60.

16. Walker BF, French SD, Grant W, Green S. A Cochrane review of combined chiropractic interventions for low-back pain. Spine. 2011;36:230-42.

17. Stochkendahl MJ, Sorensen J, Vach W, Christensen HW, Hoilund-Carlsen PF, Hartvigsen J. Cost-effectiveness of chiropractic care versus self-management in patients with musculoskeletal chest pain. Open Heart. 2016;3:e000334.

18. Blanchette MA, Stochkendahl MJ, Borges da Silva R, Boruff J, Harrison P, Bussieres A. Effectiveness and Economic Evaluation of Chiropractic Care for the Treatment of Low Back Pain: A Systematic Review of Pragmatic Studies. PLoS One. 2016;11:e0160037.

19. Hebert JJ, Stomski NJ, French SD, Rubinstein SM. Serious adverse events and spinal manipulative therapy of the low back region: a systematic review of cases. J Manip Physiol Ther. 2015;38:677-91.

20. Senstad O, Leboeuf-Yde C, Borchgrevink CF. Side-effects of chiropractic spinal manipulation: types frequency, discomfort and course. Scand J Prim Health Care. 1996;14:50-3.

21. Green BN, Johnson CD, Daniels CJ, Napuli JG, Gliedt JA, Paris DJ. Integration of chiropractic Services in Military and Veteran Health Care Facilities: a systematic review of the literature. J Evid Based Complementary Altern Med. 2016;21:115-30.

22. Nielsen OL, Kongsted A, Christensen HW. The chiropractic profession in Denmark 2010-2014: a descriptive report. Chiropractic \& manual therapies. 2015;23:27.

23. Westin D, Tandberg T, John C, Axen I. GPS opinions and perceptions of chiropractic in Sweden and Norway: a descriptive survey. Chiropractic \& manual therapies. 2013;21:29. 